Srio 3

(1832-1850)

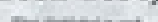

\section{On sulphocamphoric acid}

\section{Philippe Walter}

To cite this article: M. Philippe Walter (1844) On sulphocamphoric acid, Philosophical Magazine Series 3, 24:157, 157-159, DOI: 10.1080/14786444408644823

To link to this article: http://dx.doi.org/10.1080/14786444408644823

曲 Published online: 30 Apr 2009.

Submit your article to this journal 주다

LII Article views: 2

Q View related articles $\asymp$ 
less furnishes, when treated with nitric acid, a large quantity of lamellar, brilliant crystals of picic acid, and only traces of oxalic acid.

When infusion of galls is added to gelatinous apiin, liquefied by heat, no sensible change is produced, except that on cooling the mixture solidifies into an opake white mass, which again liquefies by heat. Chlorine gas, when passed into the gelatinous apiin, converts it into a yellowish matter, which is insoluble in boiling water, but soluble in alcohol and weak alkaline solutions ; there is also produced a small quantity of carbazotic acid. It appears that apiin may be classed with the substances composed of carbon, hydrogen and water, and intermediate as to gums and resins. It may be supposed that apiin exists in variable quantities on umbelliferous plants; but M. Braconnot admits that he found very little in the leaves or stalks of celery, and none in chervil.-Ann. de Ch. et de Ph., Octobre 1843.

\section{ON SULPHOCAMPHORIC ACID. BY M. PHILIPPE WALTER.}

Let a platina capsule be half filled with common sulphuric acid, gradually add to it small portions of anhydrous camphoric acid in very fine powder, stir the mixture continually, and the camphoric acid dissolves, forming a perfectly limpid solution; the sulphuric acid should be in considerable excess. Nordhausen and anhydrous sulphuric acid may be used instead of common; but they do not answer the purpose so conveniently.

If the mixture of the two acids be largely diluted with water, the anhydrous camphoric acid being but slightly soluble in water, is entirely precipitated, which proves that it is simply dissolved in the sulphuric acid, and that this acid has not acted upon it.

If, however, the mixture be cautiously heated to between $105^{\circ}$ and $120^{\circ} \mathrm{F}$., the surface becomes covered with bubbles of gas, and at $150^{\circ}$ the disengagement is rapid and considerable; on examination it was found to be carbonic oxide free from sulphurous and carbonic acid; the heat was continued in a water-bath for about an hour, when the mixture had assumed a brown tint. It was then largely diluted with water and suffered to remain one or more days, during which the unaltered camphoric acid was deposited, and the solution acquired a green colour owing to the formation of a new product. The camphoric acid being separated by filtration, the green-coloured solution is to be exposed in vacuo over a vessel containing sulphuric acid, and in a day or two crystals of some hundredths of an inch in length are formed, which are frequently of a green colour, so as to give rise to suspicion of the presence of copper; but it is derived from the imperfect precipitation of the green colouring matter formed.

These crystals, after proper draining and pressure on filtering paper, are to be dissolved in very strong alcohol, and the solution, by exposure to spontaneous evaporation, yields crystals which are to be again dissolved in water, and the solution, by evaporation over a waterbath, yields colourless crystals, which are sulphocamphoric acid; these, after draining, are dried by exposure to the air.

This acid yielded by analysis,- 


$\begin{array}{lr}\text { Carbon } \ldots \ldots & 37 \cdot 82 \text { or } 9=54 \\ \text { Hydrogen } \ldots \ldots & 7 \cdot 02 \text { or } 10=10 \\ \text { Sulphur ..... } 11.21 \text { or } 1=16 \\ \text { Oxygen } \ldots \ldots & \frac{43.95}{100^{\circ}} \text { or } 8=\frac{64}{144}\end{array}$

'These crystals appear, however, to contain three equivalents of water, two of which they lose, as well as their form, by exposure to sulphuric acid in vacuo, and also by heat, but the third equivalent is lost only when the acid is combined with bases.

Anhydrous camphoric acid, as indeed also appears from the constitution of the potash salt, must consist of

\begin{tabular}{|c|c|c|c|}
\hline \multicolumn{4}{|c|}{ Nine equivalents of carbon } \\
\hline Seven & $\ldots$ & hydrogen & \\
\hline One & $\ldots$ & sulphur. & 16 \\
\hline Five & $\ldots$ & oxygen. & 40 \\
\hline
\end{tabular}

The properties of crystallized camphoric acid containing the three equivalents of water are, that the form is that of six-sided prisms; they are colourless, their taste so very acid as to affect the teeth, and extremely soluble in water. If small crystals be thrown on water they dissolve almost instantaneously with rapid motion. The acid containing one equivalent of water dissolves in water with still greater rapidity and motion; it is very insoluble in common or absolute alcohol; soluble in $x$ ther, insoluble in cold oil of turpentine, and very slightly dissolved by it when hot, and insoluble in sulphuret of carbon, whether cold or hot. When the crystallized salt is heated on platina it loses its water of crystallization, fuses, and becomes of a red colour; when more strongly heated it blackens, is completely decomposed, yielding abundant white vapours, and disappearing without leaving any residue.

Nitric acid dissolves this substance slowly when cold; when boiling it dissolves it rapidly without decomposing it and without evol. ving red vapours ; it is dissolved by cold, and more readily by hot, hydrochloric acid; it has been shown by the method of preparation that sulphocamphoric acid is soluble in sulphuric acid moderately heated; when cold it is but slightly so. When the sulphuric solution is rather strongly heated it assumes at first a red tint, which on raising the temperature becomes gradually black, and when the heat is raised to ebullition the colour becomes of an intense black, the acid is decomposed, and sulphurous acid is evolved. When put into contact with anhydrous sulphuric acid it loses water, becomes of a blood-red colour and is decomposed.

When chlorine gas is passed into an aqueous solution of sulphocamphoric acid, an oleaginous compound is formed, which sinks to the bottom of the vessel; it is insoluble in water, and burns with the green flame, which is characteristic of the presence of chlorine; bromine attacks it with the disengagement of white vapours of hydro. 
bromic acid, and converts it into a body containing bromine, which is heavier than water; it is not acted upon by iodine when they are triturated together.

It appears from M. Walter's experiments that anhydrous camphoric acid is composed of

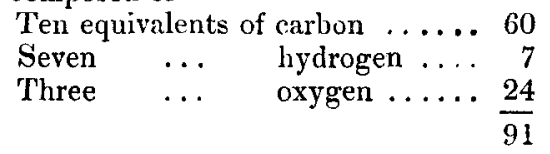

and he considers that when this is acted upon by sulphuric acid, it takes one equivalent of oxygen and yields one equivalent of carbon, which escape in combination as oxide of carbon, as already noticed; the sulphuric acid remaining combines with the camphoric acid, minus the equivalent of carbon to form the su]phocamphoric acid.

M. Walter observes that the most remarkable character of the sulphocamphoric is this, that whereas in other acids formed by the reaction of sulphuric on organic compounds, the sulphur exists in them in the state of hyposulphuric acid, in this acid it is in that of sulphurous acid.-Ann. de Ch. et de Phys., Octobre 1843.

\section{METEOROLOGICAL OBSERVATIONS FOR DECEMBER 1843.}

Chiswick.-December 1. Overcast: clear. 2. Frosty haze : very fine: hazy. 3. Hazy : cloudy and mild, 4. Drizzly. 5. Cloudy and fine. 6. Clear and fine, 7. Drizzly. 8. Very tine. 9. Foggy, 10. Foggy : fine. 11. Very fine. 12. Dense fog. 13. Foggy : bazy cluuds. 14. Clear and fine. 15, 16. Fine, with clouds. 17. Slight haze : clear and fine: foggy. 18. Foggy. 19, 20. Hazy. 21. Overcast. 22. Very fine : thickly overcast. 23. Cloudy and mild. 24. Clear and fine. 25. Hazy : overcast. 26. Drizzly: foggy. 27. Hazy. 28. Cloudy and fine: hazy. 29. Hazy. 30. Orercast: rain. 31. Cloudy : squally with rain.-Mean temperature of the month $2 \cdot 26^{\circ}$ above the average.

Bostor.-Dec. 1. Cloudy. 2. Fine. 3. Fine, beautiful halo round the moon eight o'clock r.M. 4. Fine. 5. Cloudy, 6. Fine. 7. Rain, 8. Fine. 9. Fine : rain P.M. 10. Foggy. 11, 12. Cloudy. 13, Foggy. 14. Fine. 15. Fine: rain early A.M. 16. Cloudy. 17. Fine. 18-20. Foggy. 21. Cloudy. 2224. Fine. 25-28. Foggy. 29, 30. Cloudy. 31. Fine--N. B. This is the driest month since February 1832.

Sandwick Manse, Orkney-Dec. 1, 2. Cloudy. 3. Drizzle. 4. Fine. 5, 6. Heavy showers. 7. Rain : showers. 8. Showers : clear. 9. Cloudy. 10,11. Cloudy: clear. 12. Clear. 13. Cloudy. 14. Cloudy : heavy showers. 15, 16. Showers. 17. Drizzle. 18. Showers. 19. Cloudy : fine. 20. Fine. 21. Fine : cloudy : fine. 22. Showers : fair : showers. 23. Showers : fair: damp. 24, 25. Clear : fair. 26. Damp : drizzle. 27. Clear : fine. 28. Clear. 29. Cloudy. 30. Rain : drizzle. 31. Showers : hail-showers.

Applegarth Manse, Dumfries-shire.-Dec. 1. Hoar frost. 2. Thick fog. 3-7. Showers. 8. Fair. 9. Fog and rain r.M. 10-13. Cloudy and rain. 14. Fair. 15. Slight shower. 16. Fair. 17. Fair and fine, 18. Fair though dull : shower P.M. 19. Fair. 20. Showery. 21. Fair, but thick fog. 22. Very wet and stormy. 23. Slight showers. 24. Slight showers A.M. 25. Showers. 26. Rain P.M. 27. Fair, but cloudy. 28. Slight showers. 29, 30. Fair, 31. Rain.

Mean temperature of the month .....................4.46.4.

Mean temperature of December $1842 \ldots \ldots \ldots \ldots \ldots \ldots \ldots . . . .46 \cdot 05$

Mean temperature of spring-water ....................... $46 \cdot 1$ 